\title{
Age-Dependent Changes in Bone Mineral Density and Body Composition in Middle-aged and Elderly Women: Role of Growth Hormone, Insulin-like Growth Factor-I and Insulin- like Growth Factor-binding Protein-3
}

\author{
Toshitsugu Sugimoto and Kazuo Chihara \\ Third Division, Department of Medicine, Kobe University School of Medicine, Hyougo, Japan
}

\begin{abstract}
The present study was performed to investigate age-dependent changes in bone mineral density (BMD) and body composition, and the role of growth hormone (GH), insulin-like growth factor-I (IGF-I) and IGF-binding protein-3 (IGFBP-3) in these changes in healthy middleaged and elderly Japanese women. BMD and body composition [bone mineral content (BMC), lean body mass (LBM) and fat] were measured by dual energy X-ray absorptiometry. BMD, BMC and LBM declined with aging, while fat mass did not. Plasma IGF- I and IGFBP-3 levels also declined with aging. Urinary GH, plasma IGF-I and IGFBP-3 levels were positively correlated with BMD and BMC, even when BMD was adjusted for age and body size. The plasma IGF-I level was positively correlated with LBM. GH and IGFBP-3 levels also showed the tendency to be correlated with LBM. The urinary GH level was negatively correlated with fat mass, whereas plasma IGF-I and IGFBP-3 levels were positively correlated with fat mass. The GH-IGF-I-IGFBP3 axis positively regulates bone and muscle mass, while GH and IGF-I-IGFBP-3 negatively and positively regulate fat mass, respectively.
\end{abstract}

Key words: GH, IGF-I, IGF-binding protein-3, bone mineral density, body composition

\section{Introduction}

Aging is associated with body compositional changes such as a decrease in bone mass. Growth hormone (GH) secretion as well as plasma levels of insulin-like growth factorI (IGF-I), an anabolic factor for bone, and IGF-binding protein-3 (IGFBP-3), a modulator

Correspondence: Dr. Toshitsugu Sugimoto, Third Division, Department of Medicine,Kobe University School of Medicine, 7-5-1, Kusunoki-cho, Chuo-ku, Kobe-shi, Hyougo 650 Japan of IGF action, also decrease with aging (1). Although there is evidence that GH plays an important role in the maintenance of bone mass in adulthood and participates in the process of bone remodeling partly via IGF-I (2-7), it is unclear how the GH-IGF-I-IGFBP3 axis is involved in the age-dependent decrease in bone mass. On the other hand, the recent development of dual energy X-ray absorptiometry (DEXA) has made it possible to analyze body composition such as lean body mass (LBM) and fat mass easily and precisely 


\section{Sugimoto et al.}

(8). Our previous study indicated that DEXA is useful for the analysis of body composition at different ages and in both sexes (9). Although $\mathrm{GH}$ acts on bone, muscle and fat, it is unknown how the GH-IGF-I-IGFBP-3 axis is involved in age-dependent changes in body composition. The present study was performed to investigate age-dependent changes in bone mineral density (BMD) and body composition, and the role of GH, IGH-I and IGFBP-3 in these changes in healthy middle-aged and elderly Japanese women.

\section{Subjects and Methods}

\section{Subjects}

The subjects were 165 Japanese healthy women, aged 43 to 88 years, who visited our out-patient clinic for bone mass examination. They agreed to participate in this study and gave informed consent. None were known to have liver or renal dysfunction, nutritional disorders or metabolic diseases which might cause changes in body composition. All subjects were free of drugs known to influence bone and calcium metabolism.

\section{Measurements of BMD and Body Compo- sition}

Total and lumbar BMD as well as bone mineral content (BMC), LBM and fat were measured by DEXA (QDR-2,000, Hologic). The percentage of BMC, LBM and fat was calculated by dividing each absolute value of body composition by total body mass.

\section{Biochemical Measurements}

GH concentration divided by the early morning urinary creatinine level was used as an index of endogenous GH secretion. Urinary GH levels were measured by sandwich enzyme immunoassay $(10,11)$. Plasma IGF-I levels were measured by radioimmunoassay (RIA) after acid-ethanol extraction $(12,13)$. Plasma IGFBP-3 and 2 levels were also measured by RIA (14).

\section{Statistical Analysis}

Data were expressed as the meam \pm SEM. Statistical analysis was performed using Student's t-test. p-Values less than 0.05 were considered significant. Regression analysis was performed using the computer program of Abacus Concepts, Statview (Abacus Concepts, Inc., Berkely, CA). Simple regression analysis was performed to assess the linear relationships between the study parameters, and Pearson's correlation coefficients were calculated.

\section{Results and Discussion}

\section{Role of GH-IGF-I-IGFBP-3 Axis in Age- Dependent Bone Loss}

Fig. 1 shows changes in total BMD with aging in middle-aged and elderly women. The total BMD clearly decreased with aging. Plasma levels of IGF-I and IGFBP-3 also decreased with age (Fig. 2), which is consistent with a previous report (1). In contrast, the plasma IGFBP-2 level increased with age. Since there is evidence that the plasma IGFBP-2 level increases under conditions where there is insufficient IGFBP-3 to bind the available IGFs (15), it may function as an additional IGF carrier, when IGFBP-3 level is inadequate.

We next examined whether the GH-IGF-I- 


\section{Bone Mineral Density and Body Composition}

IGFBP-3 axis was involved in an age-dependent decrease in BMD. As shown in Fig. 3, the GH, IGF-I and IGFBP-3 levels were all positively correlated with total $\mathrm{BMD}$, while the plasma IGFBP-2 level was negatively correlated with total BMD. These findings indicate an important role for the GH-IGF-I-IGFBP-3 axis in the regulation of bone mass, which is consistent with a previous report (5). Since BMD and the GH-IGF-I-IGFBP-3 axis are influenced by aging and/or body size, we next examined the relationship between BMD and the GH-IGF-I-IGFBP-3 axis when the effects of aging and body size were excluded. As shown in Fig. 4, the Z score of BMD (standard deviation of average BMD at each age) was also positively correlated with plasma IGF-I and IGFBP-3 levels. BMD/height, the most convenient index of body size adjustment (16), was also still positively correlated with $\mathrm{GH}$, IGF-I and IGFBP-3 levels (Fig. 5). BMD does not always reflect bone strength, although it is considered to account for about 75 to $85 \%$ of the varience in ultimate strength of bone

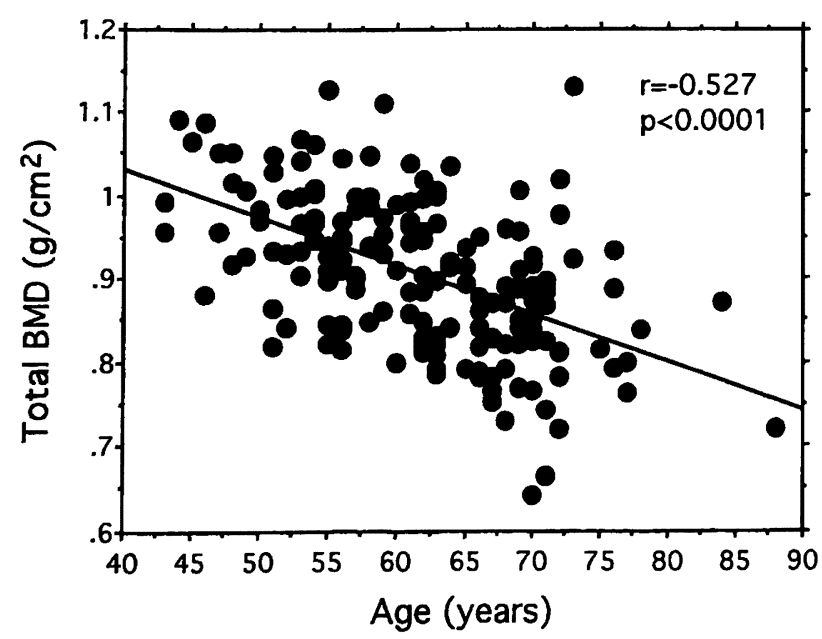

Fig. 1 Changes in total BMD with aging.
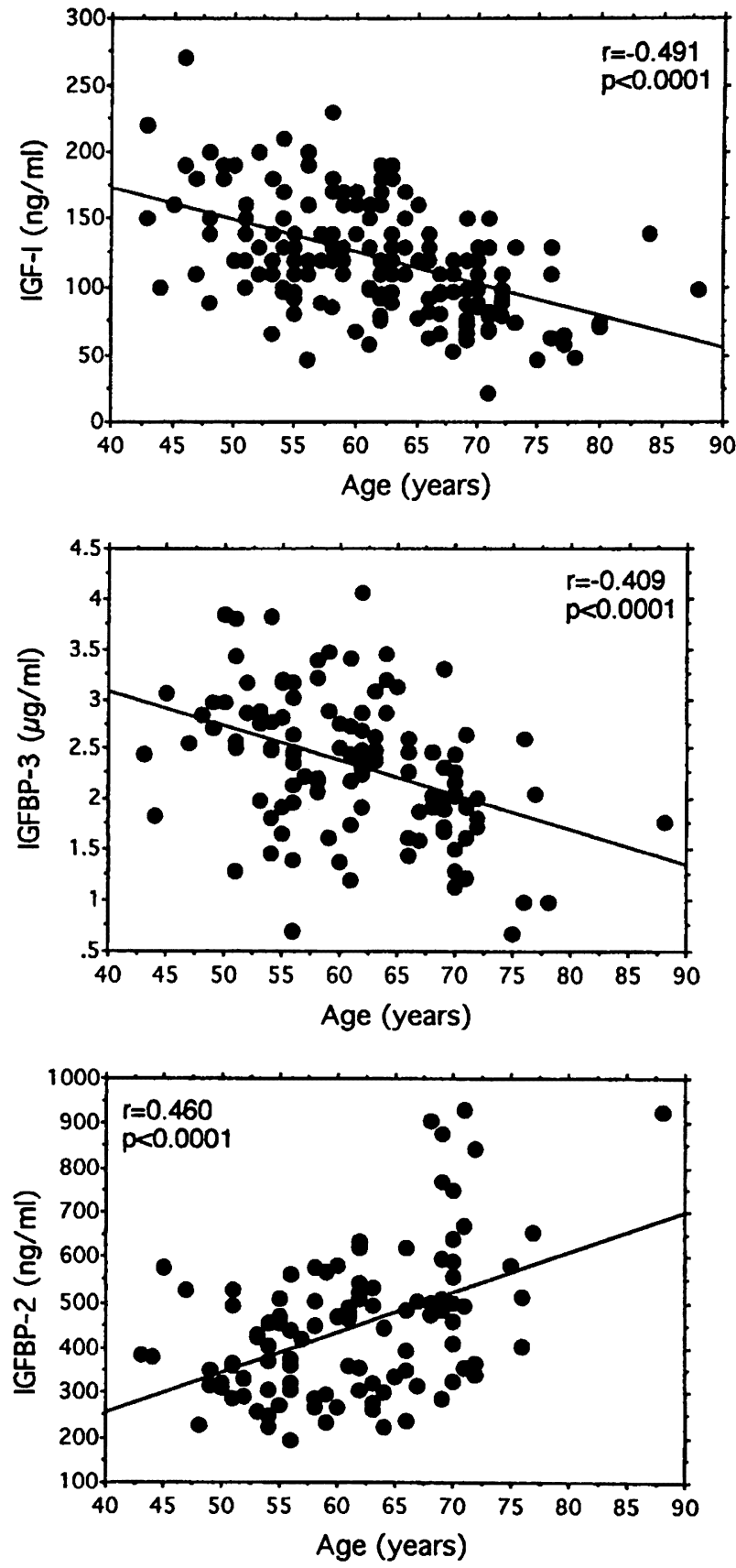

Fig. 2 Relationship between age and plasma IGFI or IGFBPs levels. 

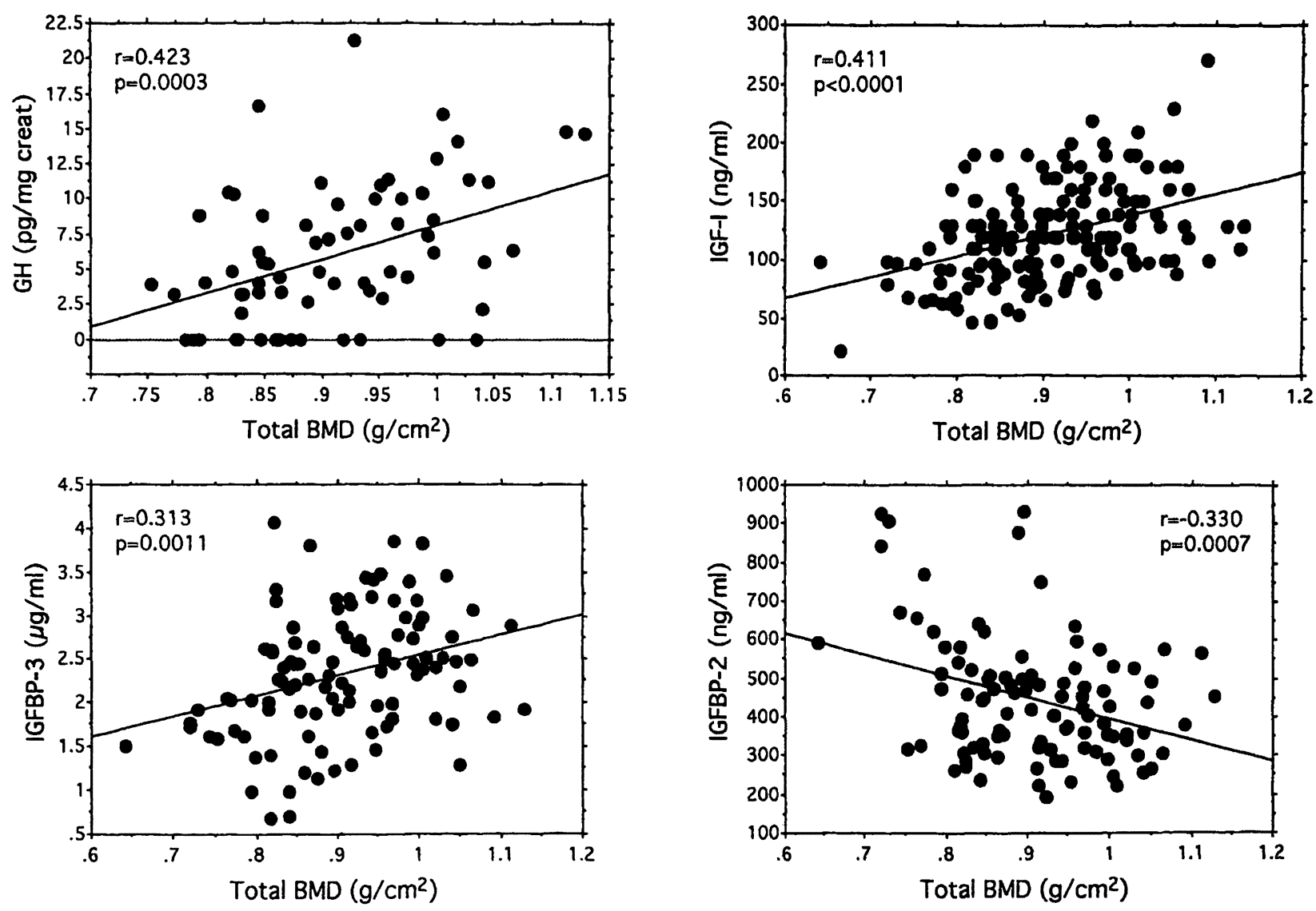

Fig. 3 Relationship between total BMD and urinary GH, plasma IGF-I or IGFBPs levels.

tissue (17). We also examined the relationship between the susceptibility to osteoporotic fractures and plasma IGF-I or IGFBP-3 levels. The subjects were classified by decade to exclude the influence of aging. As shown in Fig. 6, plasma levels of IGF-I and IGFBP-3 were significantly lower in subjects with spinal fractures, compared to those without fractures in any decade, while the plasma IGFBP-2 level was not significantly different between these two groups. These findings indicate that the GH-IGF-I-IGFBP-3 axis is important to maintain bone mass quantitatively as well as qualitatively, and that aging negatively regulates the GH-IGF-I-IGFBP-3 axis, resulting in bone loss.

Role of GH-IGF-I-IGFBP-3 Axis in AgeDependent Body Compositional Changes

We next analyzed body compositional changes with aging in middle-aged and elderly women. As shown in Fig. 7, BMC, \% BMC and LBM declined with aging, while neither \% LBM fat nor \% fat significantly changed with aging. In order to clarify whether the GH-IGFI-IGFBP-3 axis is involved in age-dependent body compositional changes, the relationship between body composition and GH, IGF-I and 


\section{Bone Mineral Density and Body Composition}
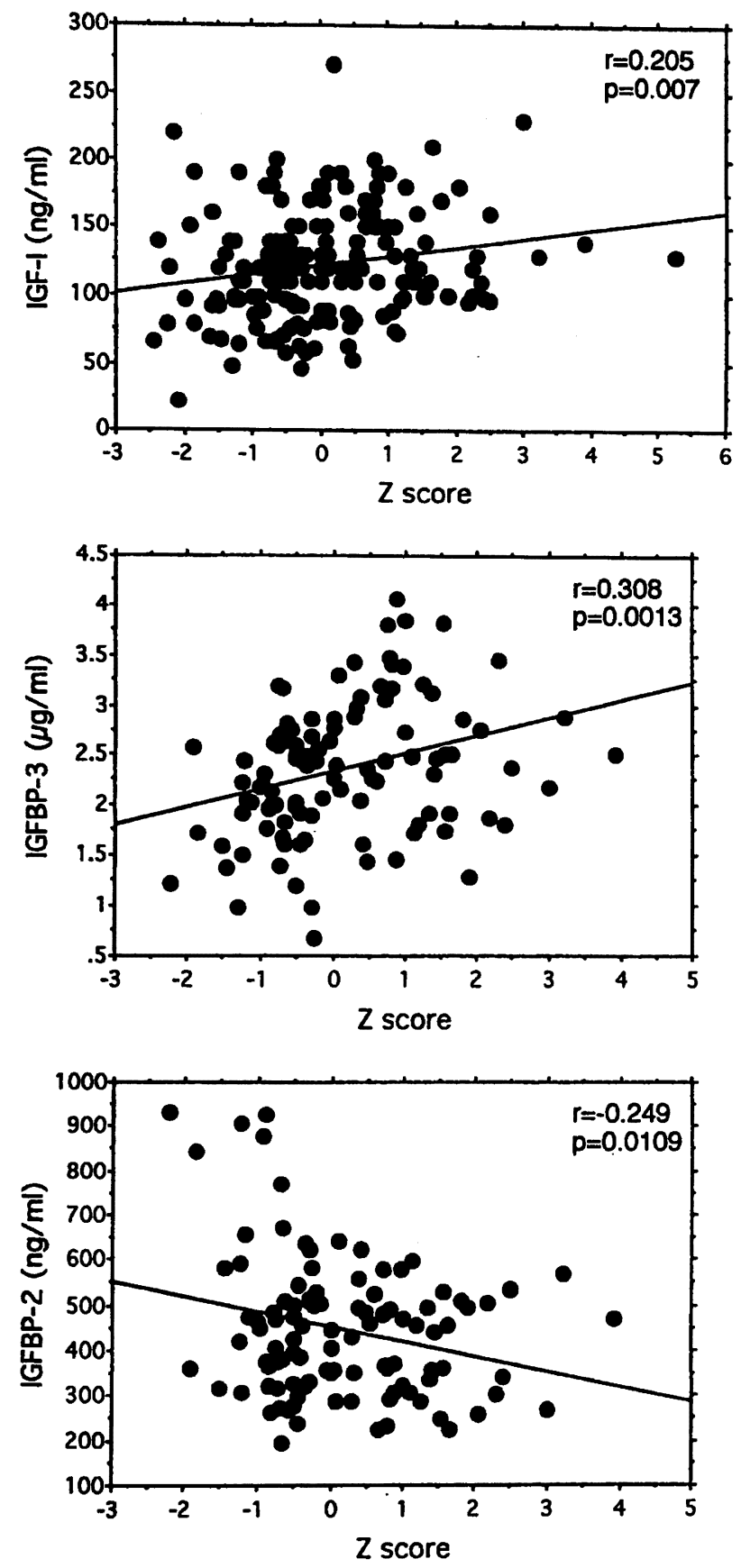

Fig. 4 Relationship between $\mathrm{Z}$ scores of lumbar spine BMD and plasma IGFI or IGFBPs levels.
IGFBP-3 levels was examined. As shown in Fig. 8, the GH level was positively correlated with $\mathrm{BMC}$, \% BMC and \% LBM, while the GH level was negatively correlated with fat and \% fat. As shown in Fig. 9, the plasma IGF-I level was positively correlated with BMC, \% BMC, LBM, fat and \% fat, and negatively correlated with \% LBM. As shown in Fig. 10, the plasma IGFBP-3 level was also positively correlated with BMC, \% BMC, fat, and \% fat, and negatively correlated with \% LBM in the same manner as the plasma IGF-I level. The relationship between the plasma IGFBP-3 level and fat was higher, compared to that between the plasma IGF-I level and fat. These findings are summarized as follows: the GH-IGF-IIGFBP-3 axis positively regulates bone and muscle mass; aging negatively regulates the GH-IGF-I-IGFBP-3 axis, resulting in bone and muscle loss; $\mathrm{GH}$ positively regulates bone and muscle mass in part via the IGF-I-IGFBP-3 pathway; GH positively regulates \% LBM, while IGF-I-IGFBP-3 negatively regulate \% LBM. These counterregulatory actions of GH and IGF-I-IGFBP-3 on \% LBM might partly explain why aging affects LBM but not \% LBM. From our data, it is not clearly why the IGF-I-IGFBP-3 system negatively affects \% LBM, but one reason might be that IGF-I and IGFBP-3 (especially IGFBP-3) affect fat mass more than muscle mass. The GH level is negatively correlated with fat and \% fat, which is consistent with previous reports suggesting a reciprocal relationship between adiposity and GH secretion $(18,19)$. In contrast, the plasma IGF-I and IGFBP-3 levels are positively correlated with fat and $\%$ fat. These data suggest that GH directly acts on fat not via the IGF-IIGFBP-3 pathway, but that IGF-I-IGFBP-3 


\section{Sugimoto et al.}
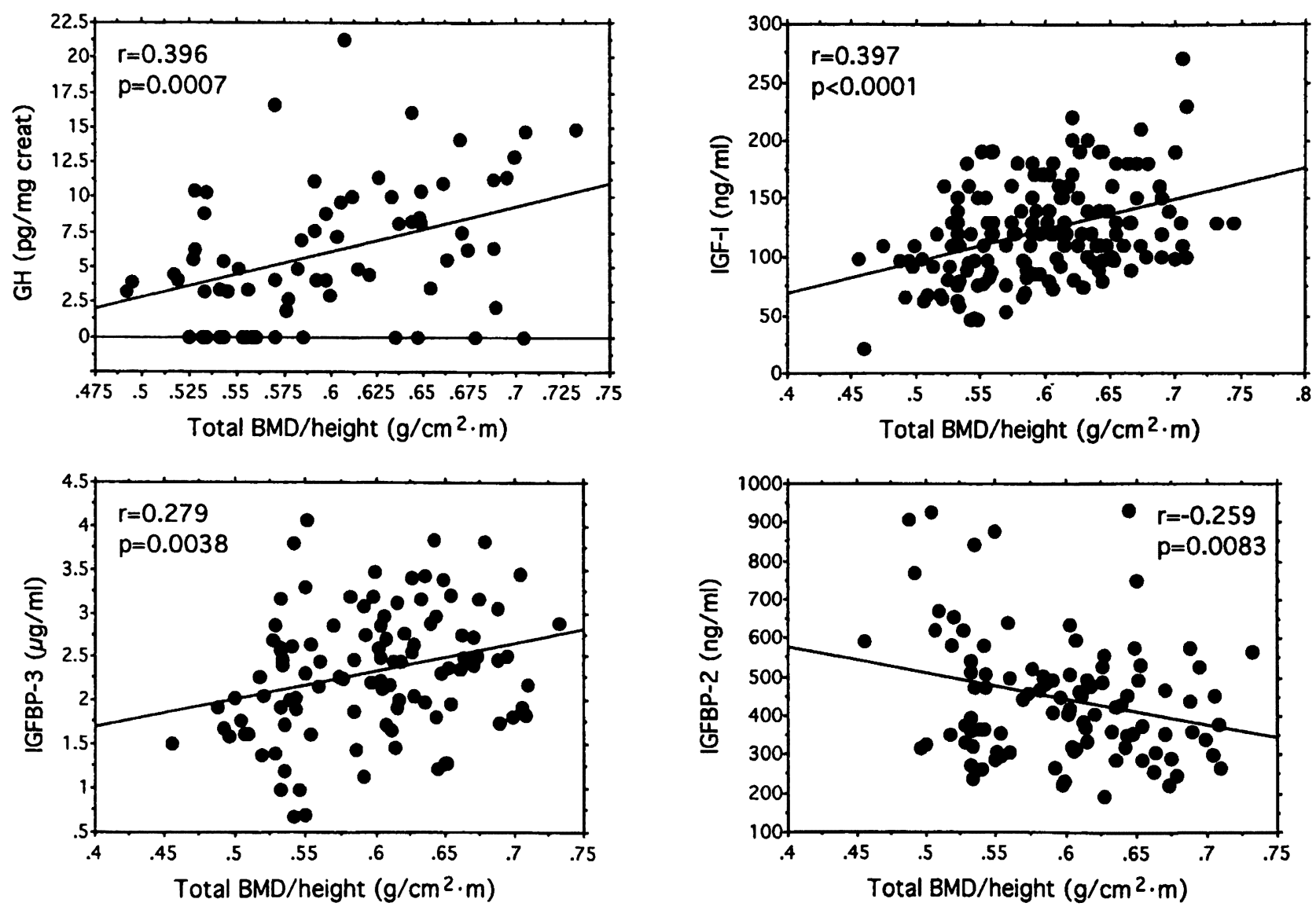

Fig. 5 Relationship between total BMD/height and urinary GH, plasma IGF-I or IGFBPs levels.

regulates fat mass in a manner independently of GH. These counterregulatory actions of GH and IGF-I-IGFBP-3 on fat might partly explain why aging did not affect fat mass. Copeland, et al. reported that the negative correlation between plasma IGF-I level and adiposity existed in men but not in women (20). This controversy might be partly explained by sex and / or racial differences.

In conclusion, the present study demonstrated age-dependent changes in BMD and body composition in middle-aged and elderly Japanese women. GH and IGF-I-IGFBP-3 play an important role in age-dependent changes in BMD and body composition. The GH-IGF-I-

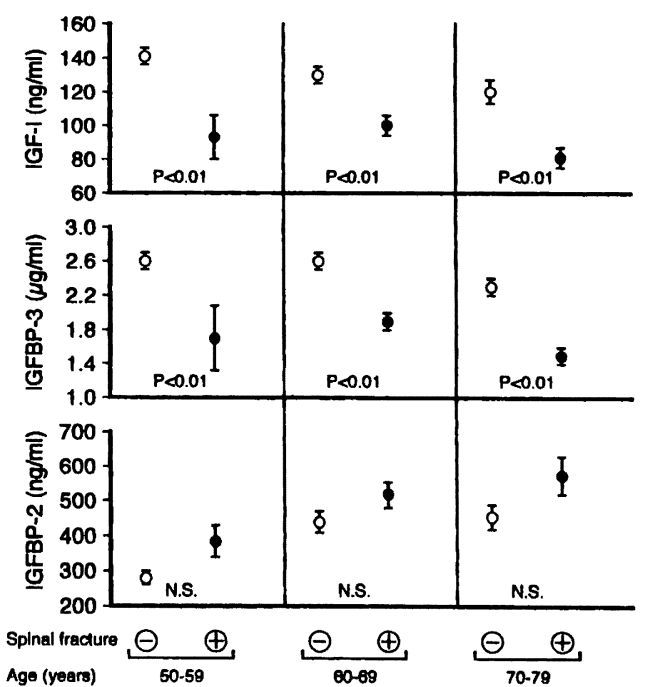

Fig. 6 Differences in plasma IGF-I and IGFBPs levels in subjects with and without spinal fracture according to decade of age. 

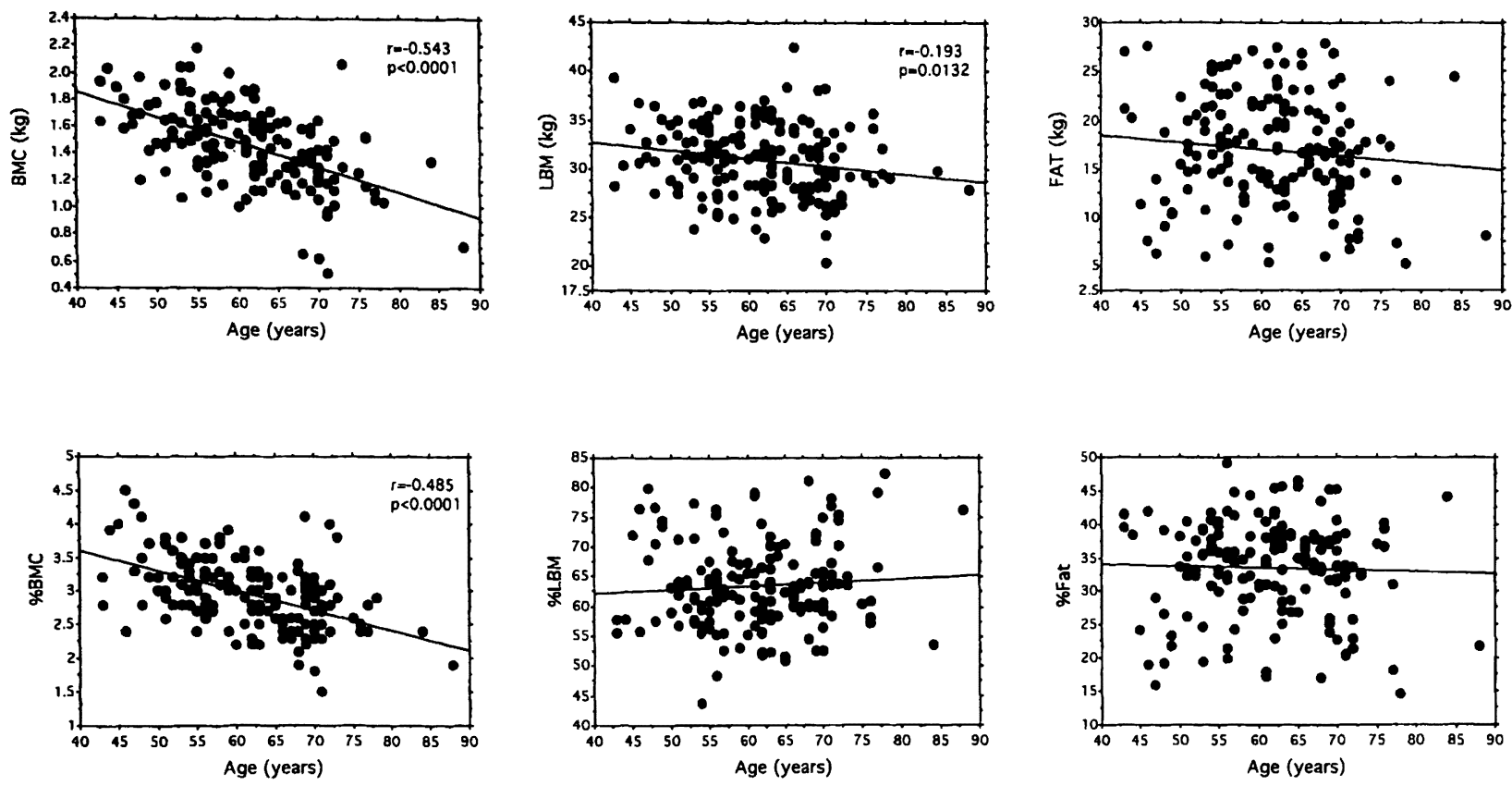

Fig. 7 Changes in body composition with aging.
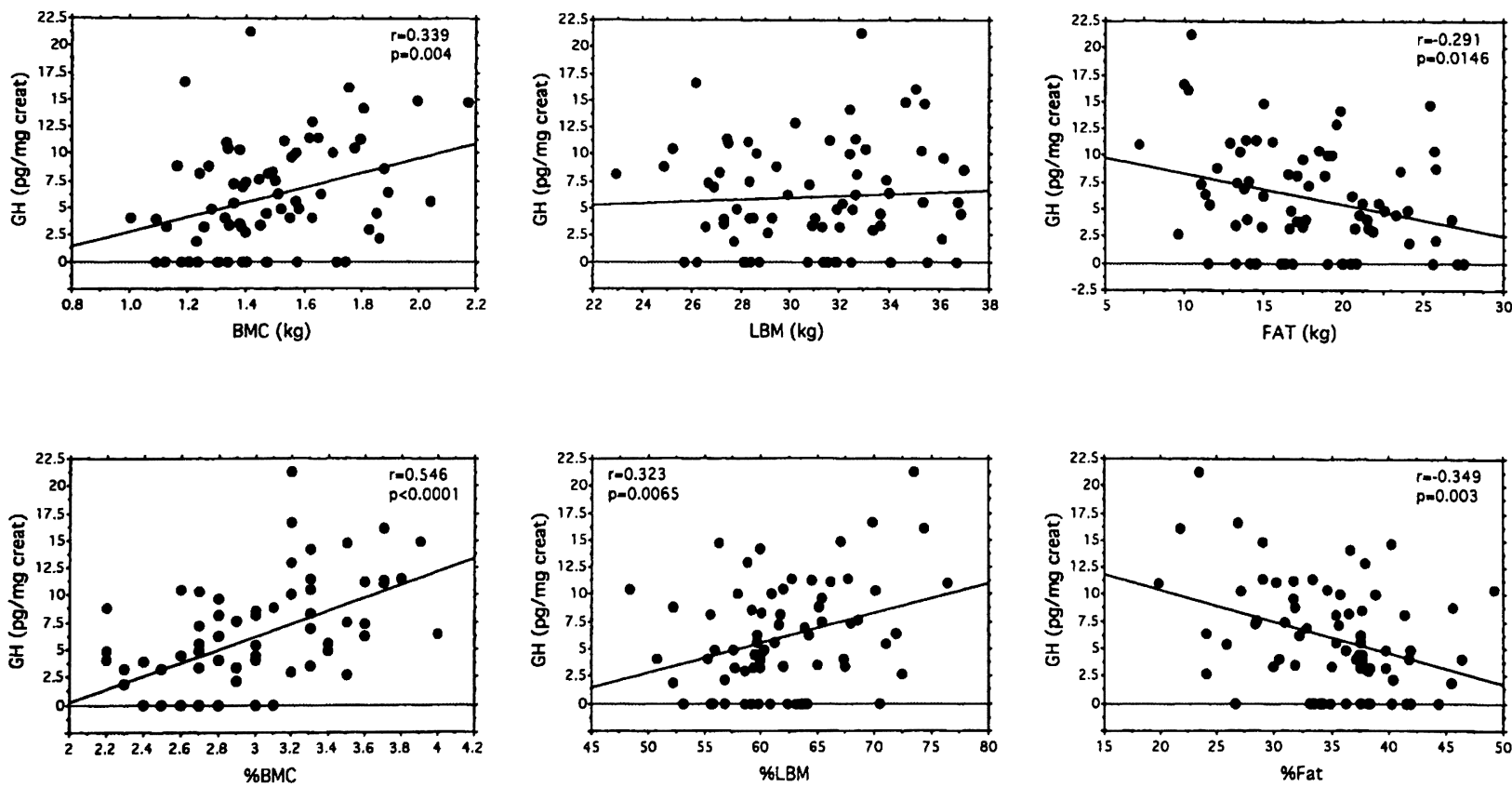

Fig. 8 Relationship between urinary GH level and body composition. 

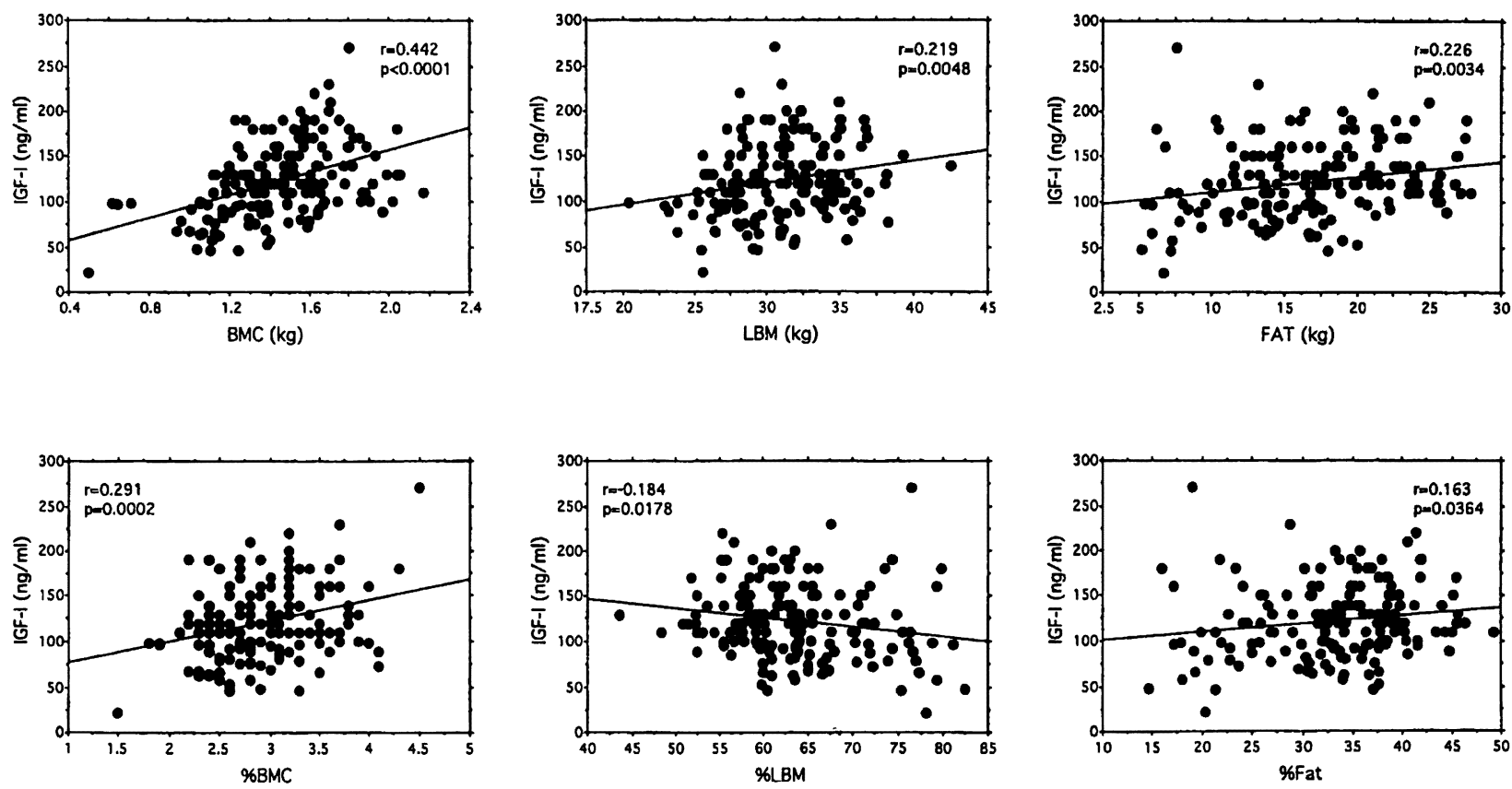

Fig. 9 Relatioship between plasma IGF-I level and body composition.
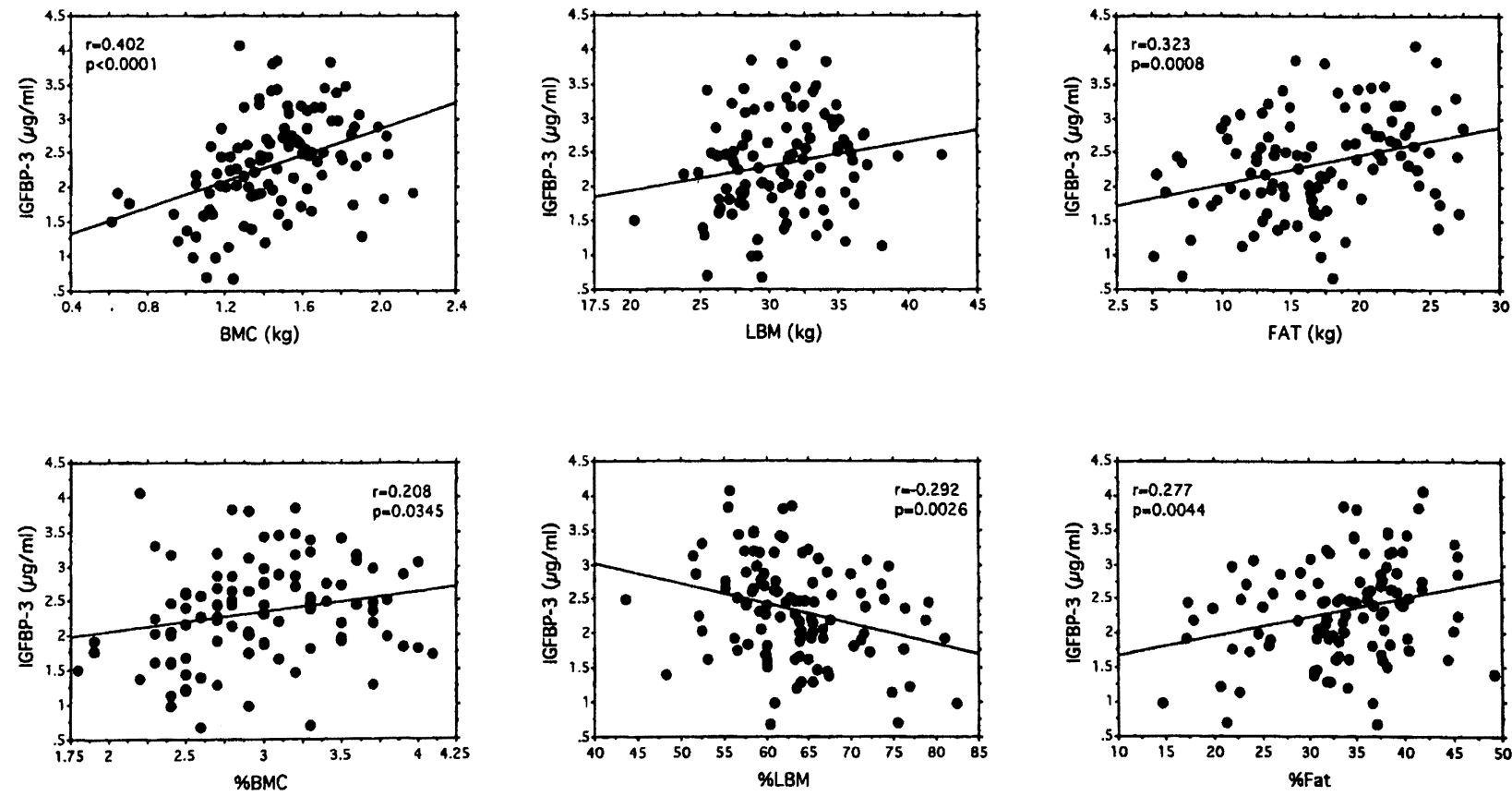

Fig. 10 Relationship between plasma IGFBP-3 level and body composition. 


\section{Bone Mineral Density and Body Composition}

IGFBP-3 axis positively regulates bone and muscle mass. In contrast, $\mathrm{GH}$ negatively regulates fat mass, while IGF-I-IGFBP-3 positively regulates fat mass.

\section{Acknowledgement}

The authors thank Mr. Fumihiko Kurimoto (Mitsubishi Kagaku Bio-Clinical Laboratories, Inc. Tokyo, Japan) for the measurements of plasma IGFBP-3 and 2.

\section{References}

1. Corpas E, Harman SM, Blackman MR. Human growth hormone and human aging. Endocr Rev 1993; 14: 20-39.

2. Rudman D, Feller AG, Nagraj HS, Gergans GA, Lalitha PY, Goldberg AF, et al. Mattson DE. Effects of human growth hormone in men over 60 years old. New Engl J Med 1990; 323: 1-6.

3. O'halloran DJ, Tsatsoulis A, Whitehouse RW, Holmes SJ, Adams JE, Shalet SM. Increased bone density after recombinant human growth hormone (GH) therapy in adults with isolated GH deficiency. J Clin Endocrinol Metab 1993; 76: 1344-8.

4. Amato G, Carella C, Fazio S, Montagna GL, Cittadini A, Sabatini D, et al. Body composition, bone metabolism, and heart structure and function in growth hormone (GH) deficient adults before and after $\mathrm{GH}$ replacement therapy at low doses. J Clin Endocrinol Metab 1993; 77: 1671-6.

5. Johansson AG, Forslund A, Hambraeus L, Blum WF, Ljunghall S. Growth hormonedependent insulin-like growth factor binding protein is a major determinant of bone mineral density in healthy men. $\mathrm{J}$ Bone Miner Res 1994; 9: 915-21.

6. Parfitt AM Growth hormone and adult bone remodelling. Clin Endocrinol 1991; 35: 467-70.

7. Nishiyama K, Sugimoto $T$, Kaji $H$, Kanatani M, Kobayashi T, Chihara K. Stimulatory effect of growth hormone on bone resorption and osteoclast differentiation. Endocrinology. 1996; 137: 35-41

8. Mazess RB, Barden HS, Bisek JP, Hanson J. Dual energy X-ray absorptiometry for total-body and regional bone-mineral and soft-tissue composition. Am J Clin Nutr 1990; 51: 1167-75.

9. Tsunenari $\mathrm{T}$, Tsutsumi $\mathrm{M}$, Ohno $\mathrm{K}$, Yamamoto Y, Kawakatsu M, Shimogaki K, et al. Age-and gender-related changes in body composition in Japanese subjects. J Bone Miner Res 1993; 8: 397-402.

10. Hashida S, Ishikawa $E$, Kato $Y$, Imura $H$, Mohri Z, Murakami Y. Human growth hormone $(\mathrm{hGH})$ in urine and its correlation to serum hGH examined by a highly sensitive sandwich enzyme immunoassay. Clinica Chimica Acta 1987; 162: 229-35.

11. Okuno A, Yano K, Itoh $\mathrm{Y}$, hashida S, Ishikawa $\mathrm{E}$, Mohri $\mathrm{Z}$, et al. Urine growth hormone determinations compared with other methods in the assessment of growth hormone secretion. Acta Paediatr Scand 1987; 337: 74-81.

12. Daughaday WH, Mariz IK, Blethen SL. Inhibition of access of bound somatomedin to membrane receptor and immunobinding sites: A comparison of radioreceptor and radioimmunoassay of somatomedin in native and acid-ethanol-extracted serum. J Clin Endocrinol Metab 1980; 51: 781-8. 


\section{Sugimoto et al.}

13. Albertsson $\mathrm{K}$, Hall $\mathrm{K}$. Growth hormone treatment in short children: Relationship between growth and serum insulin-like growth factor I and II levels. J Clin Endocrinol Metab 1987; 65: 671-8.

14. Blum WF, Ranke MB, Kietzmann K, Gauggel E, Zeisel HJ, Bierich JR. A specific radioimmunoassay for the growth hormone (GH) -dependent somatomedinbinding protein: its use for diagnosis of GH deficiency. J Clin Endocrinol Metab 1990; 70: 1292-8.

15. Zapf J, Schmid C, Guler HP, Waldvogel M, Hauri $\mathrm{CH}$, Futo $\mathrm{E}$, et al. Regulation of binding proteins for insulin-like growth factors (IGFs) in human. J Clin Invest 1990; 86: 952-61.

16. Reid IR, Plank LD, Evans MC. Fat mass is an important determinant of whole body bone density in premenopausal women but not in men. J Clin Endocrinol
Metab 1992; 75: 779-82.

17. Melton LJ, Chao EYS, Lane J. Biomechanical aspects of fractures. In; Riggs BL, Melton LJ, editors. Osteoporosis: etiology, diagnosis, and management. New York: Raven Press 1988: 111-31.

18. Elahi D, Muller DC, Tzankoff SP, Andres R, Tobin JD. Effect of age and obesity on fasting levels of glucose, insulin, glucagon, and growth hormone in men. J Gerontol 1982; 37: 385-91.

19. Meistas MT, Foster GVB, Margolis S, Kowarski AA. Integrated concentrations of growth hormone, insulin, C-peptide, and prolactin in human obesity. Metabolism 1982; 31: 1224-9.

20. Copeland KC, Colletti RB, Devlin JT, McAuliffe TL. The relationship between insulin-like growth factor-I, adiposity, and aging. Metabolism 1990; 39: 584-7. 